\title{
POLITICA Y NARCOTRÁFICO EN EL VALLE DEL CAUCA: Del testaferrato al paramilitarismo político.
}

\author{
POLITICS AND NARCOTRAFFIC IN CAUCA VALLEY STATE: From \\ testaferrrato to political paramilitarism.
}

\author{
Hernando Llano Ángel ${ }^{1}$ \\ Marcela Restrepo Hung ${ }^{2}$
}

\begin{abstract}
This paper attempts to show a comprehensive examination of the relationships between politics and narcotraffic in Cauca Valley State and how this political phenomenon derived from figureheads. Also, a reflection about the way this situation had appeared since 1990 and the way it articulated within the electoral behavior of voters in Cauca Valley State is presented.
\end{abstract}

This paper shows an analysis about figureheads and political paramilitarism and their close relationships with the Colombian Democratic Security Program and the political mutation of paramilitary groups. Finally, some relevant hypotheses about the political dynamics in Cauca Valley State, which are evidenced both in the current political crisis and the results of the last presidential elections are presented.

\section{Resumen.}

El presente artículo se ocupa, en extenso, de revisar las relaciones entre política y narcotráfico en el departamento del Valle del Cauca y cómo este fenómeno político deriva en el testaferrato. Reflexiona sobre el modo en que, desde la década de los años 90s, se venía presentando y la manera como se articula a la actividad política de los vallecaucanos.

1 Abogado. Magister en Estudios Políticos. Pontificia Universidad Javeriana. Ph.D. Ciencia Política. Universidad Complutense de Madrid. Profesor Asociado de la Pontificia Universidad Javeriana. Cali. Socio Fundación Foro Nacional por Colombia, capítulo Valle del Cauca.

2. Magister en Estudios Políticos. Pontificia Universidad Javeriana. Cali. Investigadora de la misma Universidad.

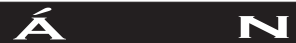

Universidad Autónoma de Manizales

\section{$\mathbf{R}$}

Año I5, Número 24, enero-julio 2008 
Avanza en un análisis sobre el testaferrato y el paramilitarismo político y sus estrechas relaciones con la Seguridad Democrática y la mutación política Paramilitar. Deja consignadas unas importantes hipótesis de la dinámica política en el Valle del Cauca que tienen expresión en la actual coyuntura política y que se expresaron en el pasado debate electoral.

\section{Un pasado presente.}

De alguna manera Cali y el Departamento del Valle del Cauca, a principios de la década del noventa, marcaban el meridiano por el cual cruzaba la compleja y ambigua relación que siempre ha existido en nuestra sociedad entre política y narcotráfico. Una relación que ha oscilado entre la connivencia de la política con el crimen, derivada de mutuos beneficios, o la confrontación visceral y terrorífica, por incompatibilidad de intereses y valores. En el polo de la connivencia, giraba entonces la relación del denominado "cartel de Cali", bajo el mando de los hermanos Rodríguez, y en el polo del terror, Pablo Escobar, con sus estructuras criminales en Medellín. No obstante, ambas formas de relacionarse con la política coincidían en el objetivo estratégico de impedir a toda costa la aplicación del temido Tratado de Extradición con los Estados Unidos. Objetivo que fue alcanzado a través del ya derogado artículo 35 de la Constitución de 1991, que prohibía la extradición de colombianos por nacimiento. En dicha coyuntura, la coincidencia de intereses los llevó a formar una coalición, asumiendo cada parte una división del trabajo según sus fortalezas. Los Rodríguez, centraron su influencia en lo que se podría denominar el testaferrato político, a través de delegatarios y funcionarios al interior de la Asamblea Nacional Constituyente, partidarios de la prohibición de la extradición, en una típica y exitosa maniobra de cabildeo político. Mientras Pablo Escobar recurría a presiones más directas y terroríficas, mediante el secuestro y asesinato de personas allegadas a las élites del poder económico y político, tales como el entonces periodista de "El Tiempo" Francisco Santos y doña Marina Montoya, cruelmente asesinada, hermana del entonces Secretario General del Presidente Virgilio Barco.

Pero antes de esta peculiar y efectiva forma de relacionarse ambos carteles con la política, tuvimos en nuestra historia reciente un episodio que marcó el nacimiento del paramilitarismo como hijo legítimo del narcotráfico, fruto de la primera coalición de estas dos organizaciones

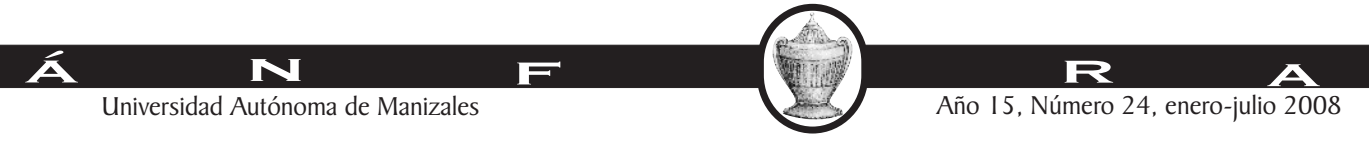


ilegales con agentes y estructuras de la inteligencia militar. El episodio fue el secuestro de Martha Nieves Ochoa por parte del M-19, que propició la conformación del MAS, Muerte a Secuestradores, y su aparición pública mediante el lanzamiento de panfletos en la ciudad de Cali el 2 de Diciembre de 1981. Luego de la violenta desarticulación de los comandos del M-19 que habían ejecutado el secuestro, incluyendo la desaparición de varios de sus miembros y la entrega a las autoridades militares del comandante Helvecio Ruiz, como presunto responsable del ilícito, fue liberada Martha Nieves Ochoa. En forma casi simultánea con esta efectiva forma de combatir el secuestro, se daba un proceso de organización de agricultores y ganaderos en Puerto Boyacá, bajo el nombre de Asociación de Comerciantes, Ganaderos y Agricultores del Magdalena Medio (Acdegam), relatado así por Iván Roberto Duque, más conocido hoy como Ernesto Báez:

"Por esos días, a finales de 1982, se dio la primera reunión de ganaderos, agricultores y comerciantes de la región. Cerca de doscientos cincuenta empresarios se organizaron para defenderse de los atropellos de la guerrilla. Con base en las disposiciones legales de 1965 y 1968 (Ley 48 del 68) que permitían a los ciudadanos portar armas con salvoconductos. El espíritu de la ley pretendía que los ciudadanos se organizaran y cuidaran sus predios con la colaboración de las fuerzas armadas. Como era algo legal surgió la primera asociación de autodefensa colectiva, Acdegam. La reunión se efectuó en Medellín porque el setenta por ciento de ellos no podía regresar a las fincas. Las FARC nunca se imaginaron que esta agremiación de damnificados de la guerrilla se convertiría en el cimiento de las autodefensas. De calcularlo nos habrían aplastado."

La primera investigación oficial que diagnosticó con lucidez el fenómeno criminal, fue llevada a cabo por el Procurador General de la época, Doctor Carlos Jiménez Gómez, quien en su informe al Presidente Belisario Betancur, en 1983, señalaba los siguientes aspectos sobre el carácter del fenómeno: "Propiamente hablando, el MAS no es una organización única sino una mentalidad de crisis y un tipo de delincuencia, manifestadas originalmente bajo la forma de una encubierta justicia privada y luego como instrumento de venganza, de castigo desproporcionado y gratuito, hasta de frivolidad en la criminalidad, en todos los órdenes de la actividad privada... Pero se engaña la opinión nacional cuando piensa que esta mentalidad y tipo de

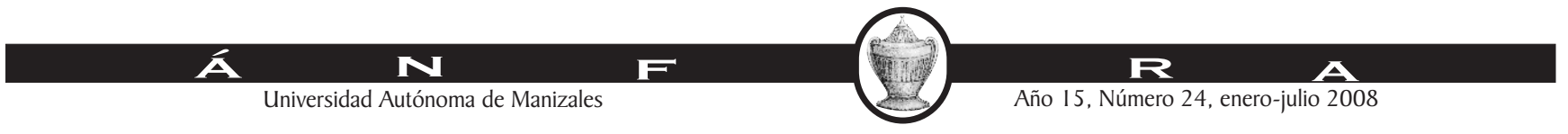


delincuencia siguen limitadas en sus objetivos en la forma que indica su nombre; lo que empezó bajo la divisa de muerte a los secuestradores se abrió luego a todo tipo de "delito", de represión y de víctima y se convirtió en "muerte a todo el mundo", a cualquiera, por todo, por los más diversos motivos. De allí la gravedad suprema de ese fenómeno, que unas veces responde a motivaciones políticas y otras a móviles puramente económicos: no es este un problema específico, sino, genéricamente, toda la problemática de la violencia nacional."

Y al referirse a la relación con miembros de la Fuerza Pública, alertaba así sobre la gravedad de sus implicaciones: "Tengo que decir que nuestra investigación encontró en los distintos lugares que personas vinculadas directa e indirectamente a las Fuerzas Armadas se han dejado arrastrar por esta corriente de la disolución nacional y han incurrido, fuera de combate, maleadas por los términos de esta larga guerra, no menos cruel por no declarada, en que nuestra sociedad ha tenido que vivir por tanto tiempo, en hechos del tipo de delincuencia que he venido analizando".

Dicho informe, que aportaba el nombre de cincuenta y nueve miembros en servicio activo de las Fuerzas Armadas implicados en graves delitos, como desapariciones y matanzas de civiles inermes, generó un fuerte rechazó del entonces Ministro de Defensa, General Fernando Landazábal Reyes, que se expresó en una cerrada solidaridad de cuerpo de las Fuerzas Armadas al donar un día de sueldo para la defensa de los sindicados, quienes además fueron investigados por la Justicia Penal Militar, no obstante haber cometido sus delitos fuera de servicio y no en cumplimiento del mismo. Se sellaba así, desde el mismo nacimiento del MAS, una relación simbiótica de carácter criminal con miembros de las Fuerzas Armadas que, con el paso de los años, se fue consolidando y hoy tiene su más clara expresión en el juzgamiento del General ( $r$ ) Jaime Alberto Uscátegui y sus revelaciones sobre la forma como se cometió la masacre de Mapiripán, en Meta, donde fueron cruelmente asesinados al menos treinta campesinos en Julio de 1997. Entre las revelaciones más graves, sobresale: "El juicio será mi gloria. Y si me voy a juicio va a ser una cuestión mucho más grave que el proceso 8.000. Mejor dicho va a ser más grave que todo lo sucedido en Colombia. Con esta cuestión (la masacre de Mapiripán), ya descubrí qué fue lo que pasó.

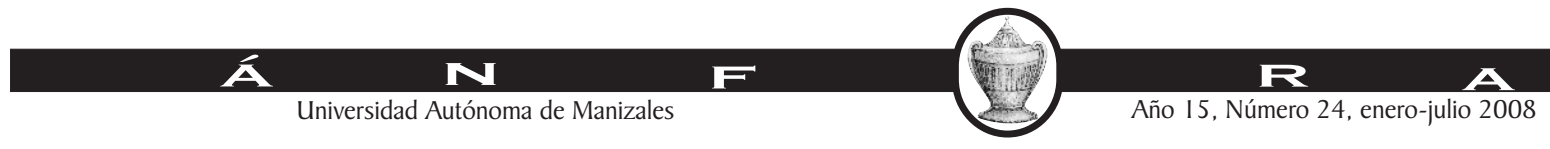


Es sumamente grave, gravísimo, porque se comprobó una cuestión que nosotros toda la vida habíamos negado, que es el vínculo de los militares con los paramilitares. Afortunadamente fueron esos mandos medios ¿no?, pero no deja de ser una realidad."

En cuanto a Cali y las expresiones del MAS en el Departamento del Valle, el mencionado informe centró su atención en la investigación del inefable crimen de "limpieza social", aportando información que comprometía gravemente algunos miembros de la Policía Nacional, dando al MAS un carácter clandestino y una estructura criminal, diferente de la que ya se gestaba en el Magdalena Medio con el embrión de Acdegam, bajo el amparo de la ley 48 de 1968, que aparecía públicamente como una organización legal y legítima. Este alumbramiento, marcará un matiz no despreciable en la evolución del paramilitarismo que se conserva hasta el día de hoy, pues mientras en el Magdalena Medio y en la Costa Caribe profundiza su raigambre social y política, en el Valle del Cauca no logra abandonar su estructura fundamentalmente clandestina y criminal, pero con numerosas ramificaciones subterráneas en sectores de la vida económica, social y política del Departamento.

Entre 1983 y 1987 proliferaron en el Departamento del Valle agrupaciones criminales bajo siglas como "Cali Limpia", "Amor a Cali" y "Palmira Eficiente", dedicadas a la supuesta "tarea" de "limpieza social", cuya acción se prolongó hasta mediados de la década del 90. Según estimativos del profesor Adolfo A. Alvarez, se calcula que entre 1992 y 1996 la tasa de muertes violentas en el Departamento osciló entre 100 y 120 por cien mil personas, cuando la media nacional era de 80; en muchos municipios del norte y centro llegaba a 200 y Cali a 120 en 1994. Es durante este período, como lo señala el Observatorio del Programa Presidencial de Derechos Humanos y Derecho Internacional Humanitario de la Vicepresidencia de la República, que "el poder del narcotráfico se apoderó del Valle del Cauca y del Norte del Cauca llevando a cabo masacres y continuos homicidios, dentro de los cuales se destacan las masacres de Trujillo y Caloto (en el Cauca), los múltiples homicidios en Miranda (Cauca), Riofrío, Tulúa y todo el Norte del Valle".

Pero este proceso no se circunscribió en el plano político al Departamento, pues a partir de la coyuntura constituyente y

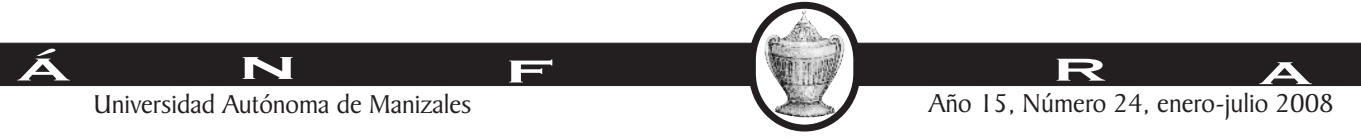


especialmente de las elecciones para Presidencia de la República y el Congreso de 1994, el cartel buscó afianzar su influencia sobre ambas instituciones, mediante la generosa financiación de las campañas políticas de Ernesto Samper y de un nutrido grupo de aspirantes al Congreso, que daría origen al famoso proceso 8.000. Dicho proceso, especialmente a partir de las revelaciones realizadas por Guillermo Pallomari, contador de los Rodríguez, develaría hasta qué punto el Cartel de Cali había ganado la connivencia de importantes sectores de la clase política nacional, en búsqueda de un sometimiento a la justicia más ventajoso del que había alcanzado el Cartel de Medellín. Sometimiento que tenía aún mayor viabilidad, después de su colaboración con las autoridades para la persecución de Pablo Escobar, a través del grupo ilegal Pepes ("Perseguidos por Pablo Escobar").

A la postre esta estrategia fracasaría, a raíz justamente de las revelaciones de Pallomari, que desatarían la purga parcial de esa clase política y la mayor crisis en la estabilidad y liderazgo del poder presidencial en nuestra historia reciente, hábilmente capitalizada por la diplomacia norteamericana en su guerra contra las drogas, al forzar la captura de los Rodríguez y la desarticulación del "Cartel de Cali". Es así como en 1997 está de nuevo reestablecida en la Constitución la extradición de colombianos por nacimiento.

\section{Del testaferrato al paramilitarismo político.}

La captura de Pallomari en Cali y la numerosa documentación contable incautada por la Fiscalía, puso de presente que la relación entre el narcotráfico y la política se había convertido en simbiótica, pues ambos se necesitaban mutuamente para sobrevivir. En su indagatoria ante los delegados de la Fiscalía colombiana, desplazados a la ciudad de Charlotte, en Carolina del Norte, el 13 de Noviembre de 1995, Guillermo Alejandro Pallomari González respondió así a la pregunta sobre la existencia de una cuenta bancaria a nombre de Export Café Ltda.: "Como se comentó anteriormente, la constitución de Export Café Ltda., empresa de fachada, se constituyó con el objetivo de abrir una cuenta corriente en el Banco de Colombia Principal, sucursal Cali, para llevar el control por separado de los cheques girados para las elecciones en el Senado y la campaña presidencial de Ernesto Samper. Los orígenes de estos dineros son así: aproximadamente el sesenta por 
ciento lo aportaron los señores Miguel Rodríguez Orejuela, Gilberto Rodríguez Orejuela, José Santacruz Londoño, Elmer Herrera Buitrago, conocido como Pacho Herrera; el cuarenta por ciento restante el señor Miguel Rodríguez Orejuela elaboró una lista de personas amigas del Departamento del Valle, las cuales en esa lista se les ponía una cuota como posible aporte a las campañas del Senado como la presidencial. Gran parte de esa lista la conformaban personas dedicadas al narcotráfico, los cuales aportaban dinero para esa cuenta corriente. Esta cuenta pudo tener ingresos alrededor de los siete mil millones de pesos, una vez cumplió el objetivo esta cuenta dejó de funcionar. Aclaro que al referirme al Senado es hablar de Senadores y Representantes a la Cámara."

Más adelante, al ser preguntado sobre la forma cómo se entregaba el dinero, respondió: "Con respecto a los dineros entregados a las personas que postulaban al Congreso, se hacía gran parte en efectivo y otras en cheque. Yo entregué personalmente trescientos millones para la campaña de Kiko Becerra, es político de filiación (sic) liberal, el dinero fue entregado en Cali en el apartamento de su señora madre, él personalmente me lo recibió, el nombre es Manuel Francisco Becerra. Personas que postularon al Congreso que tuvieron reunión personal con Miguel Rodríguez o lo llamaban por teléfono, que yo me haya dado cuenta, son las siguientes: Armando Holguín Sarriá, María Izquierdo, Rosemberg Pabón, Carlos Abadía, Orlando Vásquez Velásquez, Samuel Moreno, Carlos Espinosa Faciolince, Gustavo Espinosa, Miguel Motoa, Francisco Jattin, Gustavo Rodríguez, Alberto Santofimio, Alonso Lucio, Rodolfo González, Tiberio Villarreal, David Turbay, Manuel Francisco Becerra, Rodrigo Garavito, Hugo Castro Borja, Ana Pechtal, Roberto Gerlein y Jaime Lara."

Al analizar este tipo de relación en su incisivo y esclarecedor libro: "Mediadores, rebuscadores, traquetos y narcos. Valle del Cauca 18901997", el profesor Darío Betancourt Echeverri, misteriosa e impunemente desaparecido, señalaba lo siguiente: "El intercambio de favores entre dos poderes relativamente autónomos, se deduce en esta relación: los políticos a nombre de las instituciones del Estado, los jefes de las organizaciones mafiosas desde su control territorial mediante el ejercicio de la violencia; en otras palabras, los políticos, gracias a su acceso a la información estratégica, pueden garantizarle a estas

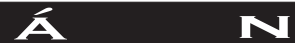

Universidad Autónoma de Manizales 
organizaciones información sobre operativos, impunidad judicial y leyes que favorezcan sus actividades y a cambio los jefes mafiosos pueden ofrecer dinero o ayudas en especie para sus campañas."

A partir de esta relación simbiótica se fue consolidando una especie de testaferrato político, puesto que destacadas figuras de la política nacional colocaron su cabeza en función y defensa de los dos intereses más codiciados por los grandes capos del narcotráfico: su seguridad e impunidad. El llamado proceso 8.000 develo parcialmente, sobre todo en el Valle del Cauca la fina red capilar que se había tejido, de alguna manera extendida por toda la geografía nacional, con una enorme capacidad de mutación y mimetismo a través de numerosos movimientos políticos camuflados tras vistosos y populares nombres, que así pasaban desapercibidos.

Uno de estos movimientos, es el Movimiento Popular Unido, regentado en el pasado por el ex Senador y convicto del proceso 8.000, Carlos H. Abadía, de quien ha heredado gran parte de su capital electoral Dilian Francisca Toro, actual Presidente del Senado, en representación del Partido de la "U". En el pasado Congreso (2002-2006) el Movimiento Popular Unido tuvo una pequeña pero significativa representación política, pues contó con dos senadores: Miguel De la Espriella Burgos, del Departamento de Córdoba y Juan Carlos Martínez Sinisterra del Departamento del Valle, y dos Representantes a la Cámara, por los mismos Departamentos: Eleonora María Pineda Arcia y Eiber Gustavo Navarro Piedrahita, quien fue despojado de su curul por el Consejo Nacional Electoral, sucediéndolo el segundo renglón de la lista del General (r) Jaime Canal Ramírez. En el actual Congreso (2006-2010), el Movimiento Popular Unido, obtiene dos curules para Carlos Arturo Quintero y Orlando Duque. Entre tanto, en un movimiento táctico, Juan Carlos Martínez Sinisterra pasa al Senado en nombre de Convergencia Ciudadana. Pero es en el orden regional donde alcanza su mayor representatividad, ya que en las pasadas votaciones para las Asambleas Departamentales (2003) obtuvo la tercera votación en los Departamentos del Valle y Chocó y la séptima y octava en Nariño y Cauca, respectivamente. En total tienen catorce Diputados en los Departamentos mencionados, incluidos entre ellos tres en el Departamento de Caquetá. Todavía mayor es su presencia en los Concejos Municipales, donde presentó doscientos cincuenta y siete 
(257) candidatos y obtuvo 95.193 votos nacionalmente, eligiendo concejales en importantes Municipios en los Departamentos del Valle, Cauca y Chocó. En Cali, se destaca Juan Carlos Abadía Campo, hijo del ex Senador Carlos H. Abadía.

Paralela a esta presencia política, hay que señalar que estos grupos afianzaron el control territorial en vastas zonas del país, financiando ejércitos privados y desplazando a miles de campesinos, mediante la ejecución de masacres y actos de intimidación terrorista. Según la Consultoría para los Derechos Humanos y el Desplazamiento Forzado (CODHES), mediante la recepción de testimonios de víctimas del desarraigo forzado de sus parcelas, se calcula que entre 1997 y 2003 los paramilitares tomaron cinco millones de hectáreas por la fuerza a nivel nacional.

En el Departamento del Valle esta violenta actividad de expropiación y control armado ilegal del territorio siempre ha estado relacionada con la expansión de los sembrados de coca y amapola, motivo por el cual una de las regiones más codiciadas ha sido el Norte del Valle y particularmente el llamado cañón de Garrapatas, además de la extensa costa pacífica y su epicentro marítimo, el puerto de Buenaventura. Darío Betancourt describe así el proceso: "La asociación existente entre el subnúcleo mafioso del norte y los otros subnúcleos mafiosos del Departamento (centro, pacífico y Cali) constituyen el Núcleo de Cali, erróneamente conocido con el nombre de cartel de Cali. Por su ubicación, las organizaciones mafiosas de la cordillera controlan un verdadero corredor estratégico en toda la cordillera Occidental, que los conecta con los subnúcleos mafiosos del Centro a partir de Tulúa y Buga; con el Norte a partir de Cartago; con el Pacífico, por sus cercanías al Terminal portuario de Buenaventura y otra serie de embarcaderos en la costa pacífica y, finalmente, con el de Cali a partir de Palmira y el aeropuerto de Palmaseca. Este corredor sirve de muro de contención a las incursiones de la guerrilla, al control de laboratorios (cocinas), localizadas en veredas de los municipios cordilleranos y en las vertientes del pacífico; además facilita el control y la vigilancia sobre la nueva carretera Panorama, que une al Norte del Valle con el Centro, con Buenaventura y con Cali, por todo el pie de monte de la cordillera Occidental." 
El control territorial se convierte, así, en el principal recurso para garantizar el sostenimiento y funcionamiento de los ejércitos privados, al permitir una fuente autónoma de ingresos derivada de la explotación de los cultivos con destinación ilícita y el aseguramiento de laboratorios y rutas expeditas para la exportación de las sustancias estupefacientes. Al respecto, la investigación sobre la economía de la guerra paramilitar, publicada en la revista Análisis Político número 53 y adelantada por el profesor Carlos Medina Gallego, señala:

"Importantes aportes hacen al sostenimiento de los paramilitares los narcotraficantes de Antioquia y el Norte del Valle, y los productores y empresarios de la coca del Tolima y del Huila. Las investigaciones realizadas a partir de las matanzas paramilitares en el Norte del Valle pusieron en evidencia el apoyo económico internacional de los circuitos comerciales del narcotráfico a este fenómeno. Según el comandante de la Tercera Brigada del Ejército, general Francisco René Pedraza, quien dirigió el operativo, el hallazgo de estos documentos es la prueba de los grandes capitales que manejan los paramilitares y que movilizan estratégicamente en el exterior.

Para el general Pedraza, todas estas pruebas pueden confirmar que la mayoría de los dineros que ingresan en las arcas de las autodefensas en el sur del país provienen de los narcotraficantes, especialmente los del Norte del Valle que los "utilizan como mecanismos para defender sus zonas de cultivos ilícitos y sus laboratorios, proteger sus capitales y camuflar sus bienes". Según los organismos de seguridad del Estado, los 12.000 paramilitares que se calculan hay en todo el país, distribuidos en doce frentes, requieren por lo menos $\$ 7.000$ millones mensuales para su mantenimiento y operación. Los investigadores creen que buena parte de esos dineros - que al año representan cerca de $100 \mathrm{mil}$ millones- se recauda en el Valle del Cauca."

Sin duda, por estas relaciones tan estrechas, es que a partir de 1999 surge el Bloque Calima de las AUC con operaciones en el norte, centro y sur del Departamento, responsable de varias masacres y múltiples desplazamientos, como una respuesta a los secuestros masivos cometidos por organizaciones guerrilleras como el ELN, que privó de la libertad a 120 feligreses en la Iglesia La María en Cali en Mayo de 1999, entre los cuales se encontraba un familiar de Joaquín Mario Valencia,

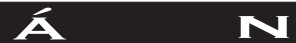

Universidad Autónoma de Manizales 
ampliamente conocido como "el caballista", recientemente extraditado y condenado en los Estados Unidos. Al año siguiente, ejecuta el ELN otro secuestro masivo en la vía al mar, afectando a personas de estrato medio de la ciudad de Cali.

Pero esta aparición de las Autodefensas en el Departamento, se da en un escenario caracterizado por la acelerada transición al interior de los diferentes sub-núcleos que integraban el desarticulado "Cartel de Cali", descrita así por el Observatorio del Programa Presidencial de Derechos Humanos y Derecho Internacional Humanitario: "A principios de los noventa, los grupos de narcotraficantes organizaron grupos armados que dirimían de manera violenta y a favor de sus pagadores, los diferentes litigios por tierras $u$ otros factores. Sus acciones se caracterizaron por la crueldad contra sus habitantes como las masacres de Caloto (Cauca), Trujillo (Norte del Valle), Miranda (Cauca), Riofrío (Norte del Valle). El renacimiento de estas organizaciones coincidió con la definición de una nueva cúpula de narcotraficantes cuyo poder preponderante tiende hacia una nueva hegemonía, luego de la entrega de los grandes capos y la muerte de otros. Los vacíos de poder se redefinieron violentamente, lo cual se refleja en el aumento del homicidio a partir de 1998, consecuencia de las múltiples disputas. El aumento de la actividad armada de la guerrilla y la realización de secuestros masivos, entre otros, a partir de 1998, facilitaron el desarrollo de alianzas entre diversos sectores de la vida económica y social vallecaucana, legales e ilegales, que utilizaron como plataforma militar y punto de confluencia, el aparato armado de los carteles. La aparición de las Autodefensas en el Valle del Cauca en 1999 con el Bloque Calima, grupo de justicia privada o paramilitar, y su expansión a lo largo de los años subsiguientes, no es solo el producto de una reacción por las acciones militares de la guerrilla como la toma de rehenes llevadas a cabo por el ELN. Es, ante todo, el lógico resultado de una compleja estrategia de posicionamiento de las nuevas elites del Valle y la necesidad de garantizar los canales de sus principales fuentes de financiación, tanto legales como ilegales."

Entre estas fuentes de financiación, destaca la extensa, selvática e inhóspita región de la costa pacífica, cuyo eje dinamizador es el puerto de Buenaventura, convertido en bastión estratégico por el control de rutas para la exportación de cocaína. De allí que sea un teatro de 
enfrentamientos donde confluyen todos los actores armados, especialmente a partir de la presencia del llamado "Bloque Pacífico" de las Autodefensas, que ejecuta en Abril de 2001 la matanza del Alto Naya con un saldo de por lo menos cuarenta víctimas entre campesinos e indígenas. Esta masacre se encuentra enmarcada en la lucha entre las FARC y las AUC por el control de esta zona estratégica para la exportación de estupefacientes. Sobre el particular, especialmente ilustrativo es el informe del Observatorio de la Presidencia de la República, que señala: "Durante la permanencia de las AUC en la zona, se enfrentaron, inicialmente contra miembros del Frente José María Becerra del ELN y luego, en su descenso hacia la vertiente del Pacífico por el río Naya, contra miembros del Frente 30 de las FARC. La respuesta de la Fuerza Pública a la alerta de la comunidad y de la Defensoría del Pueblo, con un amplio dispositivo de despliegue, llevó a un revés inicial de la incursión paramilitar, que sumado al continuo hostigamiento por parte de la guerrilla, especialmente el Frente 30, derivó en la desaparición temporal de dicho Bloque. Como resultado de los operativos militares la Armada capturó a casi 80 miembros de dicha agrupación y abatió a varios más. De estos, 70 serían condenados a cuarenta años de prisión por los delitos de desplazamiento obligado, homicidio agravado y concierto para delinquir, además de una multa de 340 millones como indemnización por cada una de las víctimas.

\section{Actores Mutantes inciertos en un escenario Electofáctico en consolidación.}

Si algo se puede concluir después del anterior panorama, cuyo resultado es un complejo y sangriento sincretismo político, producto de la amalgama entre elecciones, narcotráfico, guerrilla y crímenes de lesa humanidad, es que sus actores protagónicos van adquiriendo una identidad mutante. Identidad que va modificándose imperceptiblemente, conforme varían las relaciones de fuerza en el terreno político y militar, particularmente en la arena nacional e internacional, a partir de los proyectos estratégicos que resultan airosos en el debate electoral. Como consecuencia de lo anterior, ha venido consolidándose en el orden nacional, en especial a partir de dinámicas regionales y locales, lo que bien podría denominarse un Régimen Electofáctico, pues en últimas han sido los poderes de facto quienes han tenido la mayor capacidad política decisoria, con fundamento en sus

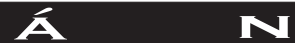

Universidad Autónoma de Manizales 
ingentes recursos económicos y militares, sobre el resultado de las elecciones.

Sin duda, lo anterior se puede constatar en las últimas cuatro elecciones presidenciales, pues es imposible explicar el triunfo de Gaviria sin el magnicidio de Galán; la postrera victoria de Samper sin la generosa contribución del narcotráfico; el ascenso de Pastrana sin el veto de las FARC contra Serpa y, la primera administración de Uribe sin la campaña de miedo e inseguridad infundida en la ciudadanía por la FARC, con el telón y terror de fondo de los fatídicos hechos del 11 de Septiembre de 2001. Lo que ha venido cambiando en cada una de estas administraciones es el rol jugado por estos actores mutantes, pues sus identidades y papeles se han mutado y trocado de acuerdo con el escenario nacional e internacional, como con el libreto escrito y representado por cada Presidente y sus contrapartes.

Así las cosas, durante el proceso constituyente el narcotráfico desempeñó simultáneamente el rol de narcoterrorista, encarnado por Pablo Escobar, pero también de actor político en cabeza de Gilberto Rodríguez, el "ajedrecista", como representante de una gran coalición de capos, que patrocinó la presencia de algunos delegatarios y funcionarios al interior de la Asamblea Nacional Constituyente. Incluso las FARC, al principio reconocidas como actores políticos, al final terminaron como monstruos antidiluvianos, según la expresión del ex Presidente Gaviria y cargando el estigma de narcoguerrilla. Durante la administración de Samper se asiste al destape de la narcopolítica, con lo cual se confirma que la identidad mutante es una característica común a numerosos actores de la vida política institucional, variando sólo el énfasis puesto en sus actividades de testaferros. Pero es durante el gobierno de Pastrana y el actual, que se manifiesta con mayor transparencia la forma como los actores van mutando sus identidades, según sea su afinidad coyuntural y los réditos tácticos que pueden alcanzar de acuerdo con la política estratégica del candidato o Presidente en función.

Como ya se mencionó, en la etapa preelectoral de Pastrana, las FARC asumen plenamente su rol político, mediante la descalificación de su contrincante, Horacio Serpa, como interlocutor para un eventual proceso de paz. Ya en desarrollo del mismo y en tanto su proyecto

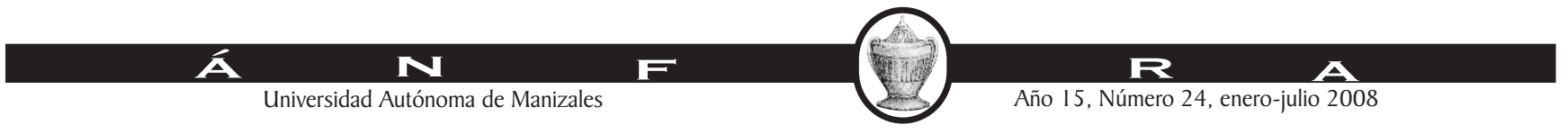


estratégico de fortalecimiento militar termina colisionando violentamente con el Plan Colombia de Pastrana, la identidad política de las FARC va mutando hacia la de un actor narcoterrorista, según el libreto diseñado por Washington después del 11 de Septiembre. Libreto por lo demás fácilmente aplicable a las FARC por sus continuas y graves infracciones del DIH contra la población civil, que precipitan el final de la zona de distensión del Caguán, al mismo tiempo que contribuyen al inobjetable triunfo electoral de Álvaro Uribe, pues éste había convertido el fin de dicha zona en una de sus principales banderas electorales, junto a la denominada política de seguridad democrática.

\section{Seguridad Democrática y mutación política Paramilitar.}

Bajo el escenario de la seguridad democrática, cuyo leit motiv es rodear de garantías y seguridad la inversión privada, especialmente la extranjera, recuperando la Fuerza Pública el control progresivo de todo el territorio nacional, las AUC aparecen como socios estratégicos, más aún cuando ya habían cumplido con éxito dicho rol en el Urabá antioqueño durante la gobernación de Álvaro Uribe Vélez. Esta coincidencia estratégica de intereses se pone de presente en los documentos programáticos de las AUC, publicados en su página Internet: "Con satisfacción podemos asegurar, hoy, que estamos cumpliendo con las expectativas de nuestros seguidores: hemos erradicado la guerrilla en tres Departamentos de Colombia, en los cuales se ha reactivado la economía, han retornado los desplazados por la violencia, existe una armonía entre los dueños del capital y sus trabajadores, hemos distribuido equitativamente miles de hectáreas de tierra entre campesinos, se han construido centros de salud, escuelas, colegios, hemos construido centenares de kilómetros de carreteras rurales; en otros cinco Departamentos la guerrilla ha perdido el control militar que, bajo la intimidación, ejercía, y es la Autodefensa quien Ilena el vacío de Estado en ellos; tenemos presencia militar, política y económica en un setenta por ciento del territorio nacional y una fuerza de apoyo social que nos permite, sin temor alguno, retar a la guerrilla para que sea el pueblo quien determine públicamente si la prefiere a ella o a nosotros".

No queda duda que durante el actual gobierno se ha venido propiciando aceleradamente y en forma transparente este proyecto de mutación de 
un actor criminal, considerando internacionalmente como terrorista, en actor político protagónico, en virtud de un habilidoso proceso de prestidigitación política, legal y militar, bajo el liderazgo presidencial y la amplificación complaciente de la mayoría de los medios masivos de comunicación.

La primera etapa se cumplió mediante la paradoja legal de obtener el Gobierno autorización para iniciar conversaciones de paz con actores delincuenciales no reconocidos como políticos, mediante la expedición de la ley 782 de 2002, que le permitió al Comisionado de Paz, Doctor Luis Carlos Restrepo, firmar el acuerdo de Santa Fe de Ralito el 15 de Julio de 2003. Acto seguido, por arte de prestidigitación presidencial y con ayuda de los poderes psíquicos del Doctor Restrepo, se les otorga el carácter de actor político en la ley 975 de 2005, más conocida como de "Justicia y Paz", al calificar en su artículo 72 que los grupos de autodefensa incurrieron en el delito de sedición pues "su accionar interfiere el libre funcionamiento del orden constitucional y legal".

La segunda etapa, corresponde al avance militar de la denominada política de seguridad democrática, cuyo éxito reconoce el estratega de las AUC, José Vicente Castaño, al declarar en reciente entrevista: "La seguridad democrática funcionó y se nos ha terminado la razón de existir. Las autodefensas nacieron porque el Estado no podía defendernos pero en este momento el Estado está en capacidad de defender a los ciudadanos."

Sin embargo en este acelerado proceso de mutación, no todas las estructuras de esa compleja y federalizada red de grupos de autodefensa, cuya principal fuente de financiación ha sido el narcotráfico, lograron entrar en el acuerdo de Santa Fe de Ralito. Aunque los obstáculos no han sido de orden gubernamental, pues el mismo Presidente Uribe superó este escollo en declaraciones a la Radio Cadena Nacional (RCN), al señalar el 7 de Junio de 2005 que: "Si la ley dice que quien hubiera incurrido en narcotráfico anterior a la pertenencia a un grupo paramilitar o guerrillero no puede participar en este proceso, poco vamos a hacer, pues mucha de esta gente había narcotraficado antes", quedaron por fuera del proceso dos grupos de narcotraficantes del Norte del Valle, bajo el mando de "Don Diego" y Varela respectivamente. 


\section{Mutaciones Inciertas}

Estos grupos, luego de la diáspora producida por la desarticulación del "Cartel de Cali", se consolidaron bajo el mando de Diego Montoya, "Don Diego" y Wilber Varela, "Jabón", quienes han estado transados en una guerra a muerte, que se calcula dejó cerca de 280 muertos durante el 2004. Desde diciembre de dicho año han buscado un acuerdo con el Gobierno nacional, quien ha autorizado al Congresista Luis Elmer Arenas Parra, del Movimiento "Vamos Colombia", para que sirva de emisario.

Mediante su conducto han realizado diversas propuestas, que van desde su entrega y sometimiento a la extradición pero "con la condición de que la pena no sea superior a diez años y no delatar a nadie", también "dicen estar dispuestos a suministrar información clave contra la guerrilla de las FARC, que permita localizar a los principales jefes subversivos... y ofrecen dejar de girarle a la guerrilla el gramaje o impuesto que históricamente le han pagado por cuidar narcocultivos y pistas clandestinas, por circulación de insumos químicos y por tráfico de pasta de coca y cocaína, que representan ingresos anuales para las FARC de cerca de 1 billón 660 mil millones de pesos, es decir el 46 por ciento del total recibido." Dicha contribución no deja de ser significativa, pues quienes conocen los antecedentes de Don Diego señalan que "a pesar de que en ocasiones sus hombres se han enfrentado con guerrilleros en el Departamento del Valle, lo cierto es que hay también informes de que lleva mucho tiempo aliado con las FARC en la producción de coca en vastas regiones de Nariño". Quizá por lo anterior en el Departamento del Caquetá, "que tradicionalmente ha sido una de las principales despensas de coca para el cartel del Norte del Valle, grupos de narcos estarían detrás de un nuevo grupo paramilitar que, también con panfletos, anunció en los próximos meses de este año el comienzo de sus acciones contra la guerrilla en el sur del Departamento".

Últimamente han intentado politizar más sus ejércitos privados, que ya dejan alrededor de 1.500 muertos, transformando "Los Machos", brazo armado de Don Diego, en un grupo de autodefensa rebautizándolo como Autodefensas Campesinas del Valle, pues según el argumento de Diego Montoya : "Todos los narcotraficantes en Colombia son paramilitares porque construyen ejércitos propios para luchar contra la

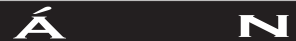

Universidad Autónoma de Manizales 
guerrilla. Además, en la medida que el Gobierno no desmovilice a los narcos, el paramilitarismo seguirá pujante, pues los desmovilizados de ahora serán reemplazados por los narcotraficantes que, con la experiencia ya vista, montarán sus ejércitos con el fin de abrirse paso un día como autodefensas en proceso de paz." Igual razonamiento comparte su enemigo, Wílber Varela, quien pretende transformar "Los Rastrojos" en Rondas Campesinas Populares.

Según los últimos documentos incautados a Henry Agudelo, "el Conejo", señalado de ser el jefe de "Ios Machos" en el Municipio de Zarzal, se ha configurado todo un plan para actuar políticamente, que va desde: "1Diseñar escudo e himno. 2- Formar emisora. 3- Conformación (sic) Fundación enfocada al apoyo poblacional (Derechos Humanos)" y entre los asuntos pendientes se anota: "Explicación de los estatutos que rigen las AUC porque no pueden ser modificados y Fundación Valle sin Hambre. Iglesias, escuelas, celebraciones especiales de la comunidad y de las fechas patrias. Brigadas de Salud y visitas médicas..." Sobre el particular puntualizó un oficial de la policía que ha intervenido en dichas pesquisas: "En síntesis, el cuaderno es un bosquejo de lo que es el proyecto que esta gente tiene para ponerse en el proceso con las Autodefensas y así granjearse los beneficios de la ley de Justicia y Paz".

Proyecto que no parece estar dispuesto a respaldar el Gobierno, pues el Ministro del Interior Sabas Pretelt ha dicho categóricamente que: "No habrá más narcos colados" y refiriéndose a los jefes del cartel del Norte del Valle enfatizó: "Seguirán siendo perseguidos por la justicia colombiana con fines de extradición, a pesar de que en los últimos meses han intentado presentar sus ejércitos personales como nuevos grupos de Autodefensas. Ellos no tienen ninguna posibilidad de ser admitidos en una negociación de paz. Son delincuentes comunes y los estamos persiguiendo para extraditarlos. La lucha contra el narcotráfico va en serio." Lucha que, desde luego, no va en serio con los narcos que clasificaron en el proceso de Santa Fe de Ralito, como los Mellizos Víctor y Miguel Ángel Mejía y Javier Zuluaga, "Gordo lindo", para mencionar los más conocidos, quienes fueron bien recibidos por sus generosos aportes para la financiación de las AUC, pues como respondió a Semana José Vicente Castaño: "En las autodefensas la mayoría éramos ilegales y con problemas jurídicos. Nunca vimos problemas que alguien con problemas jurídicos ingresara". 
Es públicamente reconocido que "Gordo Lindo", Francisco Javier Zuluaga, "heredó" el Ilamado "Bloque Pacífico", del "grupo Héroes del Chocó que pertenecía a las estructuras de Rodrigo García o Doble Cero, jefe paramilitar asesinado el año pasado en la guerra a muerte con "Don Berna", según lo informó el periódico El Tiempo en su edición del Martes 23 de Agosto de 2005, bajo el revelador titular de "Gordo Lindo, primer gallo tapado que se desmoviliza". Y como si fuera poco, en la edición del mismo diario del 3 de Septiembre de 2005, en primera página, bajo el titular de: "Se desarma el último Castaño", se informa que: "Fue con Don Berna, según las autoridades, el cerebro de la venta de franquicias paras a reconocidos narcotraficantes como Gordo Lindo, los mellizos Mejía Múnera y Miguel Arroyave".

Así las cosas, todo parece indicar, que bajo la política de la "Seguridad Democrática" y con la estratagema de la búsqueda de la paz nacional, estamos asistiendo a la más grave y exitosa metamorfosis -ni siquiera imaginada por el genio de Kafka- de un multifacético actor criminal convertido en protagonista estelar de la política nacional.

Seguramente por ello, Salvatore Mancuso, aconseja al Gobierno que negocie directamente con los narcotraficantes y se atreve hasta sugerirle una ley de sometimiento: "Cuando usted ve que los grupos narcotraficantes empiezan a organizarse como facciones militares, terroristas, e incluso con infiltraciones en la política, podemos allí ver que están buscando salidas negociadas a sus problemas ante la legalidad. Si el Estado no facilita la salida ante esas mutaciones, la violencia se perpetuará con los actores cambiando de forma. Mientras el Estado no lea correctamente las diferentes expresiones que están manifestando los narcotraficantes, el fenómeno se agravará y la paz no será alcanzable. No podemos olvidar que el narcotráfico es el banquero de la guerra". Consejo que parece haber sido tenido en cuenta en la eufemísticamente llamada ley de Justicia y Paz. Con dicha ley se estaría cerrando el ciclo de metamorfosis y descomposición de la política nacional: de la crisálida del narcotráfico nace, vuela y se posa en las cumbres estatales una vistosa mariposa con tonalidades en sus alas de rojo castaño, azul prusiano y blanco cristalino, perfecta fusión de la narcopolítica institucional, que cuenta hasta la fecha con el beneplácito de Washington en su pragmática e interesada cruzada geopolítica y militar contra las FARC.

Santiago de Cali. Octubre de 2006

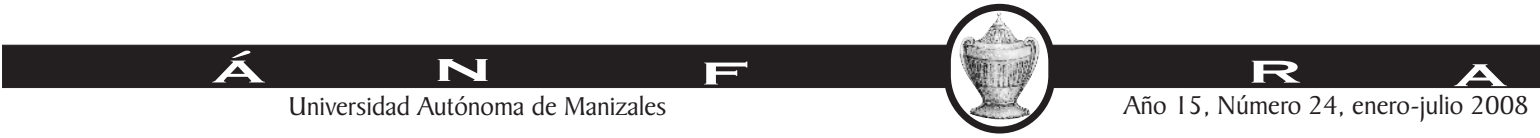

